\title{
Coexistence of two anatomical bronchial variances
}

\author{
Horiana B Grosu, ${ }^{1}$ Rodolfo C Morice, ${ }^{1}$ Sonia L Betancourt, ${ }^{2}$ Alberto L Colomer, ${ }^{3}$ Carlos A Jimenez ${ }^{1}$ \\ 1Department of Pulmonary Medicine, MD Anderson Cancer Center, Houston, Texas, USA; \\ 2Department of Radiology, MD Anderson cancer Center, Houston, Texas, USA; \\ ${ }_{3}^{3}$ Pulmonary and Critical Care and Sleep Medicine Consultants, 6624 Fannin street, Houston, Texas, USA
}

Correspondence to Dr Carlos A Jimenez, cajimenez@mdanderson.org

\section{DESCRIPTION}

A 70-year-old man with mediastinal lymphadenopathy was referred to our centre for endobronchial ultrasound with transbronchial needle aspiration. During the bronchoscopic examination, two separate anatomical bronchial variances were observed: a supernumerary 'true' tracheal bronchus branching off from the distal right lateral wall of the trachea (figure 1A) and a displaced aberrant 'tracheal' bronchus arising from the distal lateral wall of the left main stem bronchus (figure 1B). There was a normal right upper lobe bronchus but the upper division truncus of the left upper lobe bronchus was absent. CT imaging and reconstructed images of the right and left tracheal bronchi are shown in figure $2 \mathrm{~A}, \mathrm{~B}$. The term tracheal bronchus encompasses a variety of bronchial anomalies originating from the trachea or main bronchi and involving the upper lobes. These bronchi are considered supernumerary rather than displaced when they coexist with a normal type branching of the upper lobe bronchi. Anomalous bronchi are considered displaced when an aberrant bronchus is present and one branch of the upper lobe bronchus is missing. ${ }^{1}$ Normal upper lobe bronchi originate above the pulmonary artery (eparterial) on the right and below the pulmonary artery (hyparterial) on the left side. Based on their relative locations to the pulmonary artery, anomalous bronchi arising proximal to the origin of the normal upper lobes are called preeparterial on the right and prehyparterial on the left side whereas, anomalous bronchi arising distal to the origin of the upper lobe bronchi are termed posteparterial on the right and posthyparterial on the left $\operatorname{side}^{1}$ (figure 3 ). The prevalence of tracheal bronchus ranges from $0.1 \%$ to $3 \%$ on the right and $0.3 \%-1 \%$ on the left. ${ }^{2}$

\section{Learning points}

- Anomalous bronchi are usually asymptomatic and discovered incidentally.

- The coexistence of bilateral tracheal bronchi, a supernumerary pre-eparterial bronchus on the right and a displaced prehyparterial bronchus on the left as in our case, is very rare.

\section{Competing interests None.}

Patient consent Not obtained.

\section{REFERENCES}

1. Ghaye B, Szapiro D, Fanchamps JM, et al. Congenital bronchial abnormalities revisited. Radiographics 2001;21:105-19. Available from: http://radiographics. rsna.org/content/21/1/105.abstract

2. Gonlugur U, Efeoglu T, Kaptanoglu M, et al. Major anatomical variations of the tracheobronchial tree: bronchoscopic observation. Anat Sci Int 2005;80:111-15.

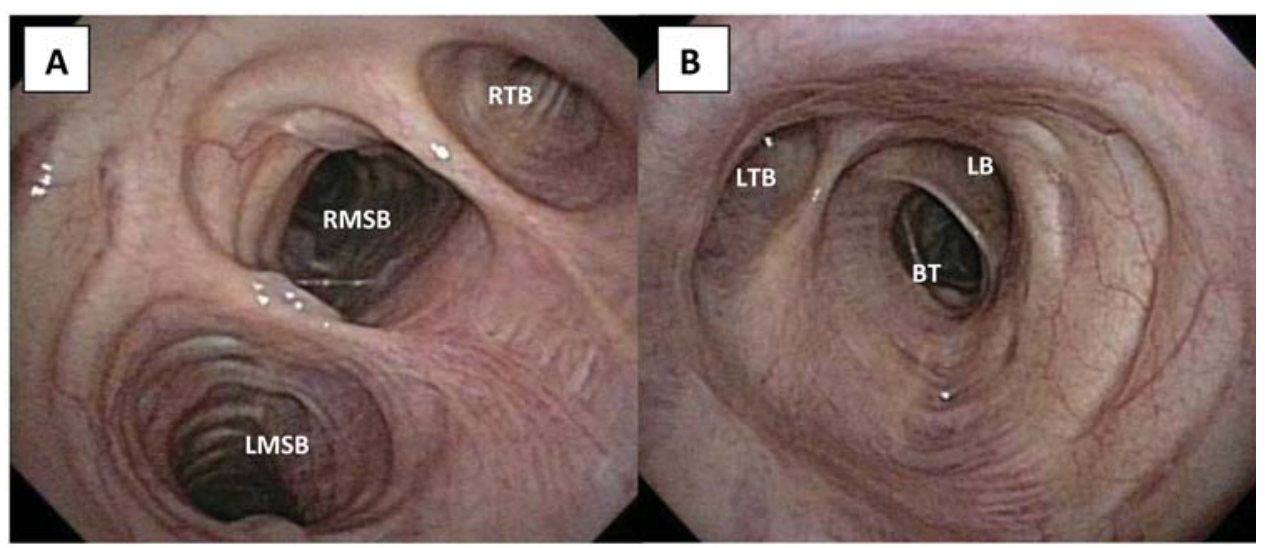

Figure 1 (A) Bronchoscopic view of distal trachea with a right tracheal bronchus. (B) Bronchoscopic view of the left main stem bronchus with a left tracheal bronchus. BT, basilar trunchus; LB, lingular bronchus; LMSB, left main stem bronchus; LTB, left tracheal bronchus; RMSB, right main stem bronchus; RTB, right tracheal bronchus. 


\section{BMJ Case Reports}
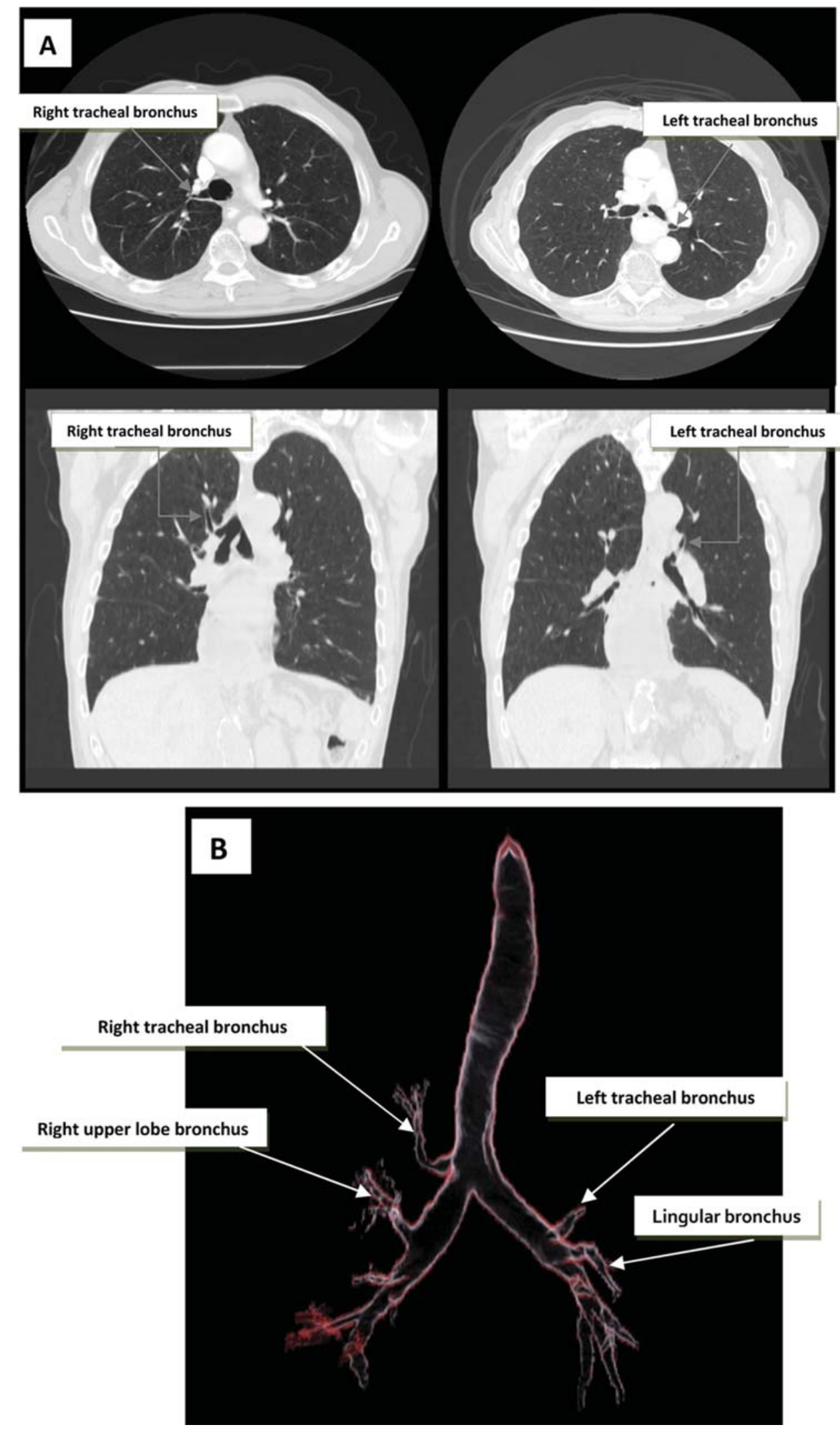

Figure 2 (A, B) CT images of the right and left tracheal bronchi. Reconstructed CT imaging of the right and left tracheal bronchi. 


\section{BMJ Case Reports}

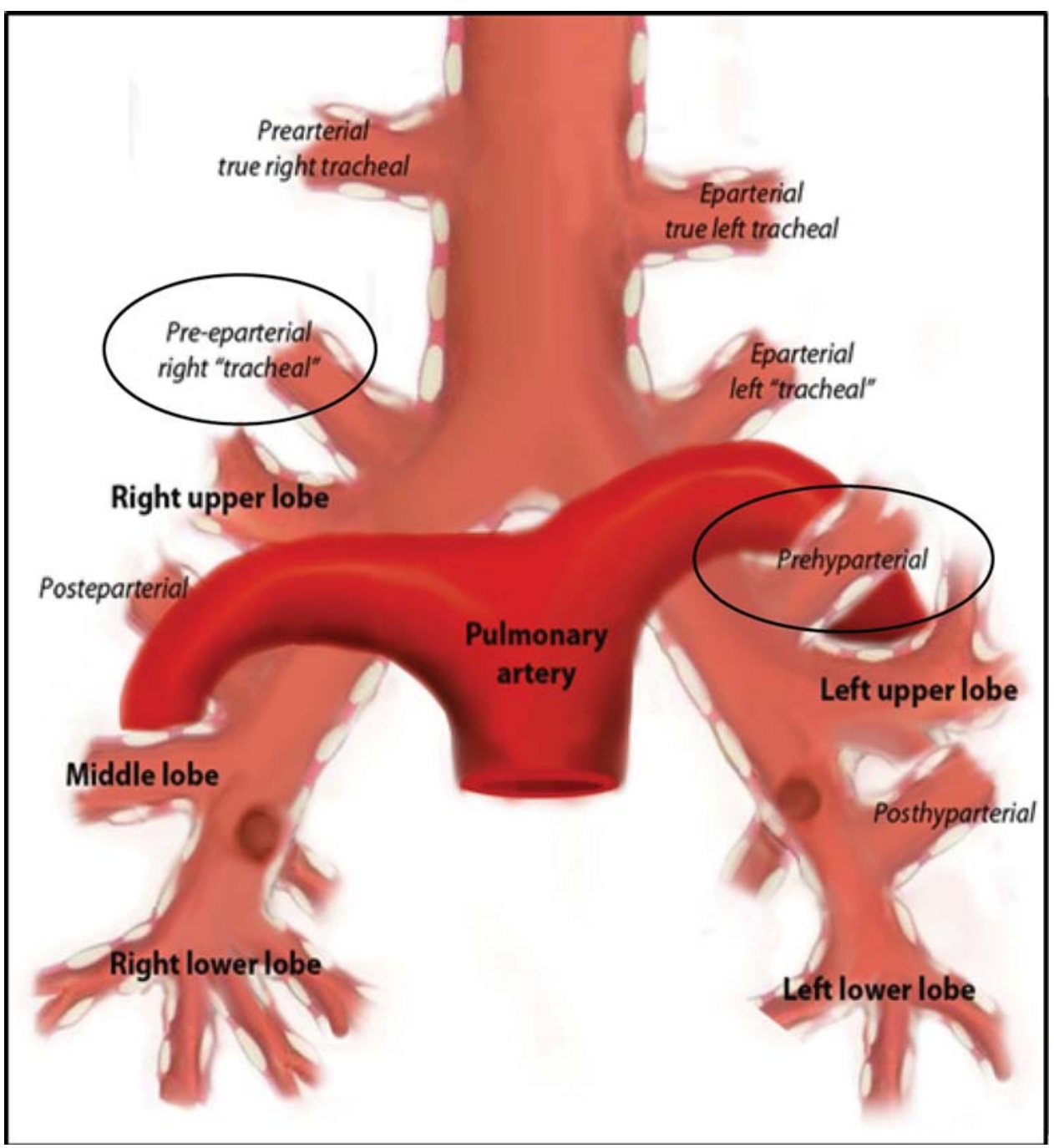

Figure 3 Nomenclature of aberrant bronchi to the upper lobes and their relationship to pulmonary vasculature. Oval enclosures highlight the two coexistent bronchial variances in this case.

This pdf has been created automatically from the final edited text and images.

Copyright 2012 BMJ Publishing Group. All rights reserved. For permission to reuse any of this content visit http://group.bmj.com/group/rights-licensing/permissions.

BMJ Case Report Fellows may re-use this article for personal use and teaching without any further permission.

Please cite this article as follows (you will need to access the article online to obtain the date of publication).

Grosu HB, Morice RC, Betancourt SL, Colomer AL, Jimenez CA. Coexistence of two anatomical bronchial variances. BMJ Case Reports 2012;10.1136/bcr.01.2012.5621, Published XXX

Become a Fellow of BMJ Case Reports today and you can:

- Submit as many cases as you like

- Enjoy fast sympathetic peer review and rapid publication of accepted articles

- Access all the published articles

- Re-use any of the published material for personal use and teaching without further permission

For information on Institutional Fellowships contact consortiasales@bmjgroup.com

Visit casereports.bmi.com for more articles like this and to become a Fellow

Keep up to date with all published cases by signing up for an alert (all we need is your email address) http://casereports.bmj.com/cgi/alerts/etoc 